\title{
Assessment of Knowledge, Attitude, and Practices about Early Childhood Caries among Postgraduates of Healthcare Professional Courses in Belagavi City: A Questionnaire Study
}

\author{
Pooja K Dialani ${ }^{1}$, Chandrashekhar Badakar ${ }^{2}$, Shivayogi M Hugar ${ }^{3}$, Priya Meharwade ${ }^{4}$, Sanjana P Soneta ${ }^{5}$, Nivedita Saxena ${ }^{6}$
}

\begin{abstract}
Aim and objective: The aim and objective of the study was to assess the knowledge, attitude, and practices about early childhood caries (ECC) among postgraduates of healthcare professional courses of Belagavi city.

Materials and methods: A sample of 400 participants were divided into four groups: dental, medical, homeopathy, and Ayurveda. An 18-item validated questionnaire containing four domains of professional demographic data, knowledge, attitude, and practices was distributed among the participants. The data collected were statistically analyzed.

Results: The descriptive analysis was used followed by Chi square for association and one-way ANOVA for comparison followed by the Karl Pearson correlation coefficient for determining the correlation between knowledge, attitude, and practices of postgraduates. The results were found to be highly statistically significant when correlation was done between knowledge, attitude, and practices among the postgraduates of healthcare professional courses $(p<0.0001)$.

Clinical significance: The findings that we get from this study are helpful in gauging the knowledge, attitude, and practices about ECC among postgraduates of healthcare professional courses in Belagavi city, which will help us to recommend the respective governing bodies to include ECC in their curriculum and train them, which will help in reducing the prevalence of ECC.

Conclusion: The study concludes that there is a need to increase the level of knowledge, attitude, and practices among postgraduates of healthcare professional courses about ECC.

Keywords: Early childhood caries, Healthcare professionals, Perception.

Journal of South Asian Association of Pediatric Dentistry (2021): 10.5005/jp-journals-10077-3066
\end{abstract}

\section{INTRODUCTION}

Globally, dental caries is claimed to be the most common chronic disease of childhood. Although dental caries has been declining around the world, the problem of early childhood caries (ECC) has remained unchanged in many parts of the world, especially in the socially deprived population.' Dental caries that affects the dentition of preschool children ( $<71$ months of age), which may even start as soon as the first primary tooth erupts, is referred to as ECC. The primary teeth are mainly responsible for a child's general health, speech development, aesthetics, and self-esteem, thus it is important to prevent and treat caries-affected teeth at the earliest. Children experiencing ECC may experience pain while eating, and thus, they are often underweight. Correspondingly, it has been seen that children having poor oral health also demonstrate poor school performance by almost 2.3 times. $^{2}$

In India, a prevalence of $44 \%$ of ECC has been reported among 8-48-month-old children. ${ }^{3}$ In rural south India, the prevalence has been reported to be $40.6 \%$ among $0-3$-year-old children. ${ }^{4}$ Despite having two dental institutions in the Belagavi city, a recent study by Sankeshwari et al. reveals a high prevalence of dental caries, i.e., $67.22 \%$ in children of this city. ${ }^{5}$

Young children and their parents visit pediatricians and primary care physicians in the initial period. The newborns and young children are generally examined in their early years of life by them, when prevention is critical and enduring behaviors are to be established; thus, these appointments must be considered

\footnotetext{
${ }^{1-6}$ Department of Pediatric and Preventive Dentistry, Kaher's KLE VK Institute of Dental Sciences, Belagavi, Karnataka, India
}

Corresponding Author: Chandrashekhar Badakar, Department of Pediatric and Preventive Dentistry, Kaher's KLE VK Institute of Dental Sciences, Belagavi, Karnataka, India, Phone: +91 9902773259, e-mail: badakar@gmail.com

How to cite this article: Dialani PK, Badakar C, Hugar SM, et al. Assessment of Knowledge, Attitude, and Practices about Early Childhood Caries among Postgraduates of Healthcare Professional Courses in Belagavi City: A Questionnaire Study. J South Asian Assoc Pediatr Dent 2021;4(1):16-21.

Source of support: Nil

Conflict of interest: None

as prospects to upsurge awareness about oral health evaluations and refer children, who are at caries-risk, to dental care. ${ }^{6}$ General practitioners, thus, must identify the necessity for and profits of early examinations so that they can commence their pivotal role in prevention of ECC. ${ }^{7}$ A considerable number of studies have been carried out in order to evaluate the knowledge, awareness, and referral practices for ECC among primary healthcare providers of the medical field, but very few have been conducted among other healthcare professionals. So, the aim of this study was to assess knowledge, attitude, and practices about ECC among the postgraduate students of dental, medical, homeopathy, and Ayurveda of Belagavi city. 


\section{Materials and Methods}

A cross-sectional, descriptive questionnaire study was conducted in the Department of Pediatric and Preventive Dentistry, KLE VK Institute of Dental Sciences, KLE Academy of Higher Education and Research, Belagavi. Ethical approval was obtained from the institutional review board (SI. No.1283) and permission to conduct the study was taken from the respective institutions from where sample were to be collected. STROBE guidelines were followed for our study. Simple random sampling was used in our study. Sample size of 326 was calculated using standard sample size formula and previous studies, which was rounded to $400{ }^{1}$ Study population included postgraduate students pertaining to various specialties, which were dental (93), medical (170), homeopathy (120), and Ayurveda (70). Subsequently among them, the participants who have given their consent from dental except pediatric postgraduates (93), medical (144), homeopathy (109), and Ayurveda (54) healthcare professional courses were included in our study.

Eighteen questions were obtained from different published articles ${ }^{1,6,8}$ and were modified covering the aspects required for this study. A pilot study was conducted and an Alpha Cronbach coefficient of 0.82 was calculated to test the reliability of the questionnaire. The questionnaire consisted of four components. The first component asked the participants to provide their professional demographic data, the second dealt with the knowledge of ECC, the third dealt with the attitude, and the last component was the practices of referral followed for prevention of ECC among healthcare professionals. The response to all the questions were measured on five-point Likert scale: "Strongly agree," "Agree," "Neutral," "Disagree," and "Strongly disagree."

The inclusion criteria for the study were the postgraduates of dental (except pediatric postgraduates), medical, and Ayurveda institutes of KLE Academy of Higher Education and research,
Belagavi, and AM Shaikh Homeopathy Institute, Belagavi. The exclusion criteria for our study were undergraduate students and the participants who do not give their consent.

The study was explained to the participants beforehand and volunteered participants were asked to gather in a lecture hall at a predetermined date and time. A written informed consent was obtained from all the participants and instruction regarding the questionnaire was given; the questionnaire was then distributed among 400 participants. Abundant time was given to the participants to complete their questionnaire; thereafter, the questionnaires were collected from them. The identity of the surveyor was kept anonymous. The data collected were compiled and statistically analyzed using the SPSS software (version 21.0 Chicago, IL, USA).

\section{RESULTS}

In the present study, all the 400 participants returned their forms and there were no dropouts. The study included $39.75 \%$ male and $60.25 \%$ female. The mean age of the surveyed professionals was 25.43 years (Table 1 ).

The association between different demographic profiles of students with levels of knowledge, attitude, and practices in the prevention of ECC was analyzed using the Chi-square test (Table 2). It was seen that all the professionals had low knowledge, attitude, and practices, which was statistically significant ( $p<0.0001)$. A questionwise response of the participants for 18 questions has been tabulated on the five-point Likert scale (Table 3).

When the comparison for knowledge was done among the professionals, dental postgraduates had higher knowledge (91.4\%) followed by homeopathy (33.94\%) and medical (29.86\%) with least being in Ayurveda postgraduates (11.11\%) (Fig. 1). With respect to attitude in prevention of ECC, dental postgraduates (76.34\%) had high attitude followed by medical (55.94\%) and homeopathy

Table 1: Demographic profile of postgraduates

\begin{tabular}{lcc}
\hline Demographic profile & No of students & \% of students \\
\hline Age groups & & \\
21-25 years & 232 & 58.00 \\
26-30 years & 168 & 42.00 \\
Mean & 25.43 & \\
SD & 1.97 & \\
Gender & & \\
$\quad$ Male & 159 & 39.75 \\
Female & 241 & 60.25 \\
Type of course & & \\
$\quad$ Ayurveda & 54 & 13.50 \\
Homeopathy & 109 & 27.25 \\
Medical & 144 & 36.00 \\
$\quad$ Dental & 93 & 23.25 \\
Total & 400 & 100.00 \\
\hline
\end{tabular}

Table 2: Association of knowledge, attitude, and practices with different types of courses by Chi-square test

\begin{tabular}{lllllll}
\hline Course & Low knowledge (\%) & High knowledge (\%) & Low attitude (\%) & High attitude (\%) & Low practices (\%) & High practices (\%) \\
\hline Dental & 8.60 & 91.4 & 23.36 & 76.34 & 83.87 & 16.13 \\
Medical & 70.14 & 29.86 & 43.06 & 56.94 & 38.19 & 61.81 \\
Homeopathy & 66.06 & 33.94 & 69.72 & 30.28 & 71.56 & 28.44 \\
Ayurveda & 88.89 & 11.11 & 85.19 & 14.81 & 85.19 & 14.81 \\
\hline
\end{tabular}


Knowledge, Attitude, and Practices about ECC

Table 3: Questionwise responses of participants

\begin{tabular}{|c|c|c|c|c|c|c|}
\hline S. no. & Questions & Strongly disagree \% & Disagree\% & Neutral\% & Agree\% & Strongly agree\% \\
\hline Q1 & $\begin{array}{l}\text { Child's overall health and development affected by } \\
\text { ECC? }\end{array}$ & 0.25 & 5.00 & 7.25 & 56.25 & 31.25 \\
\hline Q2 & Does caries occur in milk teeth? & 0.00 & 5.00 & 8.00 & 46.50 & 40.50 \\
\hline Q3 & $\begin{array}{l}\text { Do you think that the primary/milk teeth are } \\
\text { important? }\end{array}$ & 0.00 & 0.75 & 7.00 & 39.50 & 52.75 \\
\hline Q4 & $\begin{array}{l}\text { Does overnight bottle feeding affect the child's oral } \\
\text { health? }\end{array}$ & 0.25 & 2.25 & 16.75 & 42.50 & 38.25 \\
\hline Q5 & $\begin{array}{l}\text { Should parents clean their child's mouth after } \\
\text { feeding? }\end{array}$ & 0.25 & 4.50 & 11.50 & 29.75 & 54.00 \\
\hline Q6 & $\begin{array}{l}\text { Should parents clean their child's mouth after } \\
\text { feeding? }\end{array}$ & 19.25 & 47.50 & 6.25 & 20.50 & 6.50 \\
\hline Q7 & $\begin{array}{l}\text { Does the type of weaning from liquids to solids } \\
\text { makes the child more prone to acquire caries? }\end{array}$ & 0.25 & 14.00 & 29.50 & 43.75 & 12.50 \\
\hline Q8 & $\begin{array}{l}\text { Does the decayed primary teeth affect the } \\
\text { permanent/succedaneous dentition? }\end{array}$ & 6.25 & 5.25 & 19.25 & 44.50 & 24.50 \\
\hline Q9 & $\begin{array}{l}\text { Do you think medical practitioners should have the } \\
\text { knowledge about systemic effect of ECC? }\end{array}$ & 0.00 & 0.75 & 4.50 & 48.25 & 46.50 \\
\hline Q11 & $\begin{array}{l}\text { What is your opinion on child visiting their dentist by } \\
\text { their first birthday? }\end{array}$ & 5.00 & 2.75 & 28.25 & 37.50 & 26.50 \\
\hline Q12 & $\begin{array}{l}\text { Necessity of treating primary teeth even when they } \\
\text { shed off/exfoliate? }\end{array}$ & 2.75 & 5.75 & 13.50 & 39.75 & 38.25 \\
\hline Q13 & $\begin{array}{l}\text { Should a pediatric patient be referred to a specialized } \\
\text { dentist? }\end{array}$ & 0.00 & 1.25 & 10.75 & 46.25 & 41.75 \\
\hline Q14 & $\begin{array}{l}\text { Does ECC affect the child's social behavior and self- } \\
\text { esteem? }\end{array}$ & 0.25 & 4.50 & 18.75 & 43.00 & 33.50 \\
\hline Q15 & $\begin{array}{l}\text { Do you think proper diet counseling will prevent the } \\
\text { risk of acquiring } E C C \text { ? }\end{array}$ & 0.25 & 1.00 & 12.00 & 48.75 & 38.00 \\
\hline Q16 & $\begin{array}{l}\text { Should children be introduced with a toothbrush by } \\
6 \text { months of age? }\end{array}$ & 1.75 & 20.50 & 29.00 & 30.25 & 18.50 \\
\hline Q17 & $\begin{array}{l}\text { Does treating cavitated lesions at early stages is } \\
\text { beneficial in terms of total expenditure? }\end{array}$ & 0.00 & 3.50 & 12.75 & 48.75 & 35.00 \\
\hline Q18 & $\begin{array}{l}\text { Should "fluoridated toothpaste" be used in children } \\
\text { younger than } 3 \text { years of age? }\end{array}$ & 14.50 & 24.75 & 27.25 & 21.00 & 12.50 \\
\hline S. no & 6 months (\%) & 1 year (\%) & year (\%) & 6 years (\%) & \multicolumn{2}{|c|}{ Only when a problem arises (\%) } \\
\hline Q 10 & $\begin{array}{l}\text { When should the child pay a first } \\
\text { visit to a dentist? }\end{array}$ & 15.50 & & 35.35 & 34 & \\
\hline
\end{tabular}

(30.28\%) with least among the Ayurveda (14.81\%) (Fig. 1). With respect to practice of referral to a pediatric dentist in prevention of ECC, the medical postgraduates (61.81\%) showed highest followed by homeopathy (28.44\%) and dental (except pediatric postgraduates) (16.13\%) with least being in Ayurveda (14.81\%) (Fig. 1) (Table 2).

The results showed that, when the knowledge about importance of primary teeth was assessed, $52.75 \%$ strongly agreed but it was found to be statistically insignificant. Knowledge and attitude about whether decayed primary teeth will affect the permanent dentition $44.50 \%$ agreed and $p$ value of 0.0089 was obtained, which was found to be statistically significant $(p<0.05)$. Assessment of attitude regarding a child's first visit to the dentist showed $p$ value of 0.0269 that was found to be statistically significant $(p<0.05)$. Referral practices of a pediatric patient to a specialized dentist and treating the cavitated lesions at early stages for benefitting the total expenditure were found to be statistically insignificant. Also, the practices regarding prevention of ECC by proper diet counseling, introduction of toothbrush, and use of fluoridated toothpaste were found to be statistically significant $(p<0.05)$.

The comparison of knowledge, attitude, and practice among the postgraduates of four healthcare professionals was done using the one-way ANOVA test $(p<0.05)$; it was found to be statistically highly significant $(p<0.0001)$ (Fig. 2).

The correlation between the knowledge, attitude, and practices in prevention of ECC was done using the Karl Pearson's correlation coefficient and it was found to be statistically highly significant $(p=0.0001$ ) (Table 4) (Fig. 3).

\section{Discussion}

Early childhood caries is a form of dental caries that usually affects the preschool children and may start as soon as the first tooth erupts in the oral cavity. When left untreated it results in pain and potential life-threatening infections that ultimately deteriorate the overall quality of life of a child, hence the preliminary need at this 


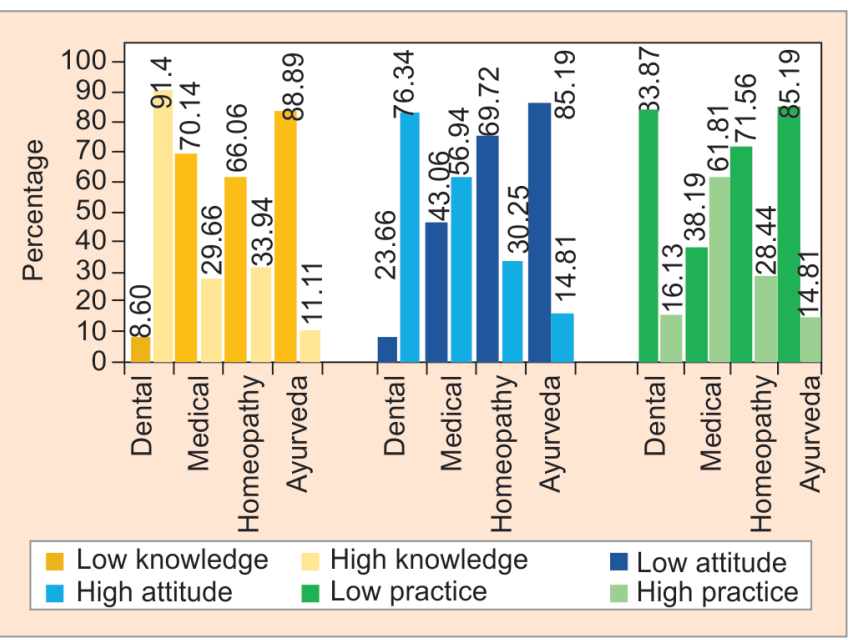

Fig. 1: Association between type of course and levels of knowledge, attitude, and practice of ECC by the Chi-square test

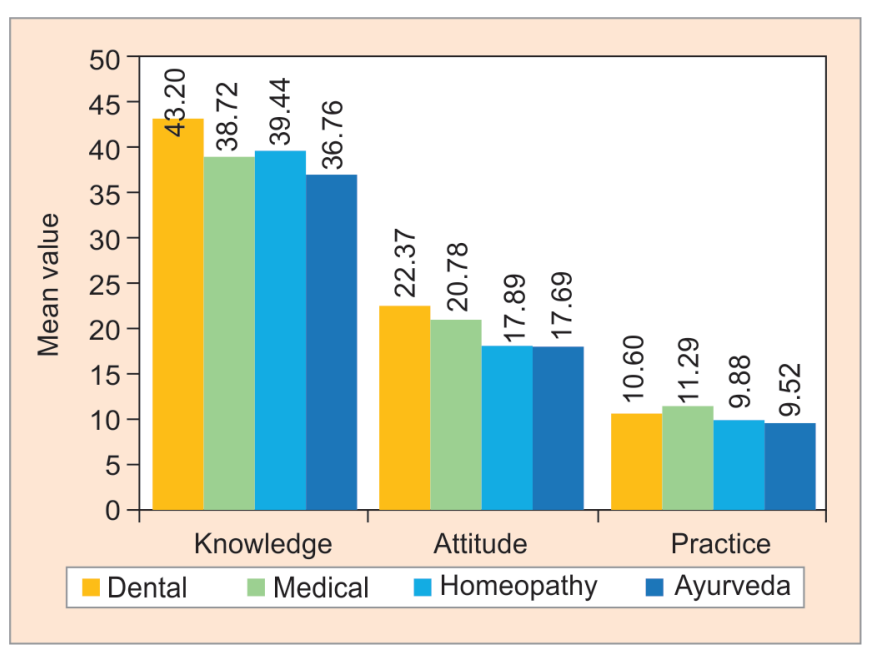

Fig. 2: Comparison of types of courses with mean knowledge, attitude, and practice scores prevention of ECC by the one-way ANOVA test

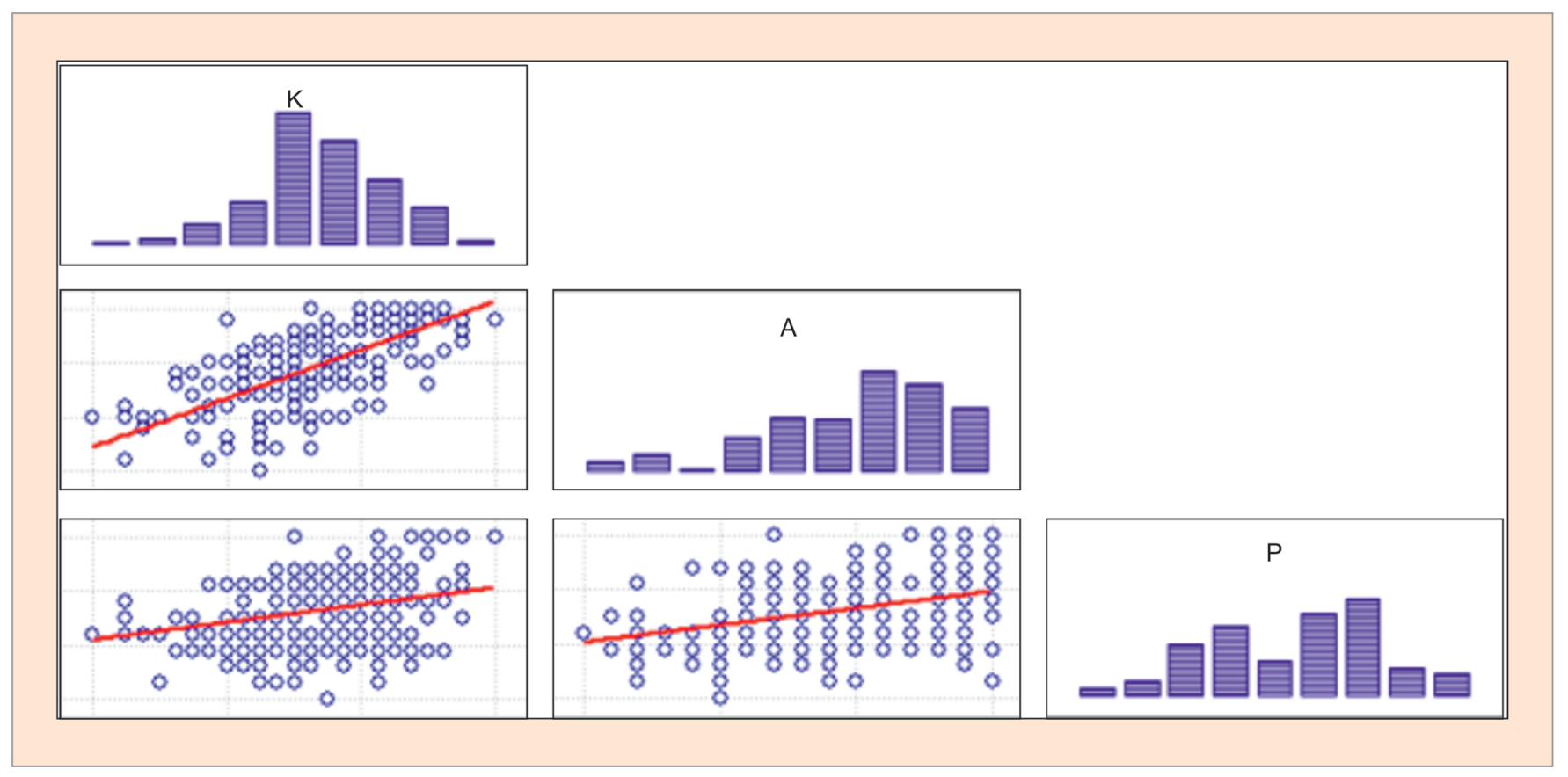

Fig. 3: Scatter diagram of correlation between knowledge, attitude, and practice scores prevention of ECC

Table 4: Correlation between knowledge, attitude, and practice scores prevention of early childhood caries by the Karl Pearson's correlation coefficient

\begin{tabular}{lrrr}
\hline & \multicolumn{3}{c}{ Correlation between } \\
\cline { 2 - 4 } Variables & rvalue & t value & $p$ value \\
\hline Knowledge vs attitude & 0.6186 & 15.7090 & $0.0001^{*}$ \\
Knowledge vs practice & 0.2614 & 5.4019 & $0.0001^{*}$ \\
Attitude vs practice & 0.3674 & 7.8804 & $0.0001^{*}$ \\
\hline${ }^{*} p<0.05$ & &
\end{tabular}

hour is primary preventive strategies for good oral health, which should be put as an essential priority in public health.

Children in their early ages are brought to the physician often more than a pediatric dentist, thus physicians play an important role in providing essential information about oral health care to the parents and also to the children at their young age. In Indian population, there is an inclination toward the use of Ayurvedic and homeopathic medicine. In a study conducted by Jawla et al., $48 \%$ of the people preferred Ayurvedic treatment and $17 \%$ preferred homeopathic treatment for common ailments. In cases of emergency, 50\% people preferred the use of allopathic medicine. ${ }^{9}$ Thus along with dental, a common effort put by medical, Ayurvedic, and homeopathic healthcare professionals is necessary to prevent ECC at preliminary stages. The American Academy of Pediatric Dentistry guidelines on infant oral health recommend that all other healthcare professionals who serve parents and infants should provide education on the etiology and prevention of ECC. ${ }^{10}$ Thus, there can be large improvement in access to dental health education and referral practices to a pediatric dentist if child oral health disease prevention and promotion strategies are incorporated into all healthcare professionals' curriculum. 
The findings of the present study reveal that there are overall low levels of knowledge, attitude, and practices among postgraduates of healthcare professional courses about ECC. Although levels of knowledge and attitude were found to be highest among dental postgraduates (except pediatric postgraduates) but practices were still found to be low in them as compared to others. About $50 \%$ of the respondents strongly agreed when asked about whether milk teeth are important for a child and $48 \%$ of the respondents agreed that decayed primary teeth affect the permanent dentition; this shows that they had the basic knowledge about primary teeth, dental decay, and its ill effects. But when they were asked if the treatment for decayed primary teeth is necessary even though they will eventually shed off, only $40 \%$ respondents strongly agreed; this threw the light on low positive attitudes of the postgraduates toward treatment of ECC. Only $40 \%$ of the respondents strongly agreed to refer the pediatric patient to a specialized dentist for the treatment and $35 \%$ of the respondents strongly agreed to the fact that treating cavitated lesions at early stages is beneficial in terms of total expenditure, which clearly shows the low level of practices being followed among the postgraduates of healthcare professional courses.

A similar study was conducted among undergraduate students by Olatosi et al., ${ }^{8}$ which stated that $32.6 \%$ of the respondents agreed that a child's first visit to the dentist should be on or before the age of 1 year, whereas in our study only $28 \%$ of the respondents strongly agreed; $81 \%$ of respondents in our study agreed that putting babies to sleep with a bottle containing infant formula/breast milk can predispose to ECC; the results were comparable to this study in which about $74.4 \%$ agreed. ${ }^{8}$

One more study was conducted by Gaddam et al. ${ }^{11}$ on knowledge and attitudes on early childhood oral health among medical and dental graduate students. About $57.14 \%$ of the finalyear dental students knew the recommended age for child's first dental visit, which was quite higher as compared to the results found in our study, which was only $28 \%$.

A research was conducted by Prathima et al. ${ }^{12}$ regarding awareness, attitudes, and practices of pediatricians regarding ECC and infant oral healthcare of children in Puducherry; 39\% of them were cognizant about maternally derived Streptococcus mutans. Similar to our study, this study also emphasized information as well as training on infant oral health care.

Indira et al..$^{13}$ piloted a research to study the knowledge, attitude, and practices of the pediatricians toward infant oral health care. The study showed that most of them were less aware of the first dental visit and ECC, which was a parallel finding in our study. All pediatricians agreed that both medical and dental professionals together are accountable for infant oral health care, which was also found in our study. A team work as well as appropriate education and training is necessary for enabling them to provide caries risk assessment and preventive oral health services, which will be advantageous for the children.

In support to the findings of our study, a cross-sectional study was conducted among pediatricians and family physicians in Riyadh city by Alshunaiber, which stated that the participants' practice was lower (42.6\%) compared with their attitude (86.1\%) and knowledge $(65.3 \%)^{14}$

Family healthcare physicians tend to play a vital role in prevention of ECC because they are the ones who primarily interact with young children before dental professionals come into role. Thus, there is a need to create more awareness among medical,
Ayurvedic, and homeopathic healthcare professionals and their postgraduates about ECC.

The discordance in attitudes and practices among the study population is directly related to their low levels of knowledge about ECC. Thus, educating the healthcare professionals regarding ECC and its effect on permanent teeth and child's health will help in elevating the levels of knowledge, attitude, and practices among them.

\section{Clinical Significance}

The findings that we get from this study are helpful in gauging the knowledge, attitude, and practices about ECC among postgraduates of healthcare professional courses in Belagavi city, which will help us to recommend the respective governing bodies to include ECC in their curriculum and train them, which will ultimately help in reducing the prevalence of ECC.

\section{Conclusion}

Thus, from this study the following conclusions can be drawn: Majority of the participants were not aware about ECC.

- A correlation exists between the quality of education and the attitude of proficiency in surveyed population.

- There is a need for education regarding ECC among postgraduates of other healthcare professional courses to broaden the horizon so as to combat the disease together.

\section{Limitations of the Study}

The study was conducted in a small geographical area and study population. In future, a study can be undertaken over a larger geographical area over a large study population.

\section{References}

1. Suma Sogi H, Hugar S, Nalawade T, et al. Knowledge, attitude, and practices of oral health care in prevention of early childhood caries among parents of children in Belagavi city: a questionnaire study. J Family Med Prim Care 2016;5(2):286. DOI: 10.4103/2249-4863. 192332.

2. Sedrak MM, Doss LM. Open up and let us in: an interprofessional approach to oral health. Pediatric Clinics 2018;65(1):91-103.

3. Ganesh A, Muthu MS, Mohan A, et al. Prevalence of early childhood caries in India - A systematic review. Indian J Pediatr 2019;86(3):276286. DOI: 10.1007/s12098-018-2793-y.

4. Henry JA, Muthu MS, Saikia A, et al. Prevalence and pattern of early childhood caries in a rural South Indian population evaluated by ICDAS with suggestions for enhancement of ICDAS software tool. Int J Paediatr Dent 2017;27(3):191-200. DOI: 10.1111/ ipd.12251.

5. Sankeshwari RM, Ankola AV, Tangade PS, et al. Feeding habits and oral hygiene practices as determinants of early childhood caries in 3- to 5-year-old children of Belgaum city, India. Oral Health Prev Dent 2012;10:283-290.

6. Dima S, Chang WJ, Chen JW, et al. Early childhood cariesrelated knowledge, attitude, and practice: discordance between pediatricians and dentists toward medical office-based prevention in Taiwan. Int J Environ Res Public Health 2018;15(6):1067. DOI: 10.3390/ ijerph15061067.

7. Stijacic T, Schroth RJ, Lawrence HP. Are Manitoba dentists aware of the recommendation for a first visit to the dentist by age 1 year? J Can Dent Assoc (Tor) 2008;74(10):903. 
8. American Academy of Pediatric Dentistry. Clinical Guidelines on Infant Oral Health Care; 2014.

9. Olatosi O, Iwuala S, Ojewola R, et al. Undergraduate medical students' knowledge and attitude on early childhood caries and infant oral health. J Pediat Dentis 2016;4(1):8. DOI: 10.4103/2321-6646.174925.

10. Jawla S, Gupta AK, Singla R, et al. General awareness and relative popularity of allopathic, ayurvedic and homeopathic systems. J Chem Pharm Res 2009;1(1):105-112.

11. Gaddam K, Kamatham R, Nuvvula S, et al. Knowledge and attitudes on early childhood oral health among medical and dental graduate students. J Educat Ethi Dentis 2014;4(1):18. DOI: 10.4103/09747761.143159 .
12. Prathima G, Kavitha M, Kayalvizhi G, et al. Awareness, attitude, and practice of pediatricians regarding early childhood caries and infant oral healthcare of children in Puducherry - a cross-sectional survey. Indian J Dent Res 2020;31(3):439. DOI: 10.4103/ijdr.IJDR_180_18.

13. Indira MD, Dhull KS, Nandlal B. Knowledge, attitude and practice toward infant oral healthcare among the pediatricians of Mysore: a questionnaire survey. Int J Clin Pediatr Dent 2015;8(3):211. DOI: 10.5005/jp-journals-10005-1315.

14. Alshunaiber R, Alzaid H, Meaigel S, et al. Early childhood caries and infant's oral health; pediatricians' and family physicians' practice, knowledge and attitude in Riyadh city. Saudi Arabia Saudi Dent J 2019;31:S96-S105. DOI: 10.1016/j.sdentj.2019.01.006. 